\title{
ECONOMIA CRIATIVA: A ALIANÇA ENTRE DESENVOLVIMENTO ECONÔMICO E A PROMOÇÃO DE DIREITOS FUNDAMENTAIS
}

\section{CREATIVE ECONOMY: THE ALLIANCE BETWEEN ECONOMIC DEVELOPMENT AND THE PROMOTION OF FUNDAMENTAL RIGHTS}

\begin{abstract}
FELIPE CHIARELLO DE SOUZA PINTO
Coordenador Adjunto de Programas Acadêmicos da Área de Direito da CAPES-MEC. Bolsista Produtividade 2 do CNPq - Brasil (Processo n. 311353/2018-5). Mestre e doutor em Direito pela Pontifícia Universidade Católica de São Paulo, foi membro do Conselho Técnico Científico, do Conselho Superior e do Comitê da Área do Direito da CAPES-MEC. Atualmente é Diretor da Faculdade de Direito da Universidade Presbiteriana Mackenzie e Professor do Programa de Mestrado e Doutorado em Direito Político e Econômico, Professor colaborador do Programa de Pós-graduação em Direito da Universidade de Passo Fundo, Membro do Comitê da Área do Direito no Programa SciELO/ FAPESP, membro Titular da Academia Paulista de Letras Jurídicas e da Academia Mackenzista de Letras.
\end{abstract}

\section{YURI NATHAN DA COSTA LANNES}

Doutorando em Direito Político e Econômico pela Universidade Presbiteriana Mackenzie, Mestre em Justiça, Empresa e Sustentabilidade pela Universidade Nove de Julho, graduado em Direito, e especialista em Direito Público e em Direito Tributário. Atualmente é Presidente da Federação Nacional de Pós-Graduandos em Direito - FEPODI (2015/2017-2017/2019), Representante Discente do Conselho Nacional de Pesquisa e Pós-Graduação em Direito - CONPEDI (2017/2020) e Professor de direito do Centro Universitário Anhanguera de Leme. 


\title{
LORRAYNE BARBOSA DE MIRANDA
}

Mestranda em Direito Ambiental pela Escola Superior Dom Helder Câmara.

\section{RESUMO}

O presente artigo tem como temática a ordem econômica e a economia criativa, com o objetivo de relacionar as estruturas constitucionais atinentes a ordem econômica prevista na Constituição Federal de 1988 e os caminhos para o desenvolvimento econômico sustentável e social a partir da ótica da economia do conhecimento. A metodologia utilizada é a dedutiva, aliada às técnicas de pesquisa bibliográfica e levantamento de dados relativos à economia criativa, com a finalidade de analisar suas implicações econômicas, jurídicas e sociais.

PALAVRAS-CHAVE: Economia criativa; ordem econômica; desenvolvimento social; direitos fundamentais.

\begin{abstract}
This article deals with the economic order and the creative economy, with the purpose of relating the constitutional structures related to the economic order provided for in the Federal Constitution of 1988 and the paths towards sustainable economic and social development from the perspective of the knowledge economy. The methodology used is deductive, coupled with the techniques of bibliographic research and collection of data related to the creative economy, with the purpose of analyzing its economic, legal and social implications
\end{abstract}

KEYWORDS: Creative economics; economic order; social development; fundamental rights. 


\section{INTRODUÇÃO}

O tema a ser desenvolvido no presente trabalho tangencia a ordem econômica na Constituição Federal de 1988 e a economia criativa como caminho para o desenvolvimento econômico e social. O texto constitucional pátrio apresenta em diversos momentos os valores fundamentais do Estado e da sociedade brasileira, quais sejam, desenvolvimento nacional, erradicação da pobreza, redução de desigualdades, justiça social, entre outros. Nesta linha, a economia criativa, entendida como aqueles setores da economia que buscam, em suma, o desenvolvimento econômico a partir da cultura, das artes, e da tecnologia, pode ser percebida por esta sociedade como um meio viável à busca destes valores constitucionais elencados, tendo em vista a experiência pouco exitosa dos modelos tradicionais de mercado em sua persecução.

A problemática que se vislumbra no presente trabalho se consubstancia na possibilidade de se verificar em que medida a economia criativa tem potencial para atuar como uma via verossímil a dinâmica de efetivação dos valores econômicos constitucionais, ao mesmo tempo em que prestigia o desenvolvimento econômico de forma sustentável, aliado ao desenvolvimento social e a proteção e efetivação dos direitos e garantias fundamentais.

Objetiva-se em um âmbito geral observar a dinâmica da ordem econômica em relação à economia criativa, passando por objetivos específicos, com a finalidade de se analisar o conjunto normativo-jurídico da ordem econômica no ordenamento jurídico brasileiro, observar sua influência no mercado global, coletar dados existentes a respeito da economia criativa, avaliar o potencial da economia criativa enquanto fomentadora de desenvolvimento econômico sustentável, e por fim, investigar os efeitos práticos da economia do conhecimento e da sua contribuição para promoção dos direitos humanos como um todo.

A metodologia adotada para o desenvolvimento do presente trabalho tem alicerce no método dedutivo baseados nos procedimentos de pesquisa de material bibliográfico. Desta maneira, buscar-se-á apresentar inicialmente questões 
relacionadas a ordem econômica na constituição federal de 1988, bem como por questões relacionadas a economia criativa, suas conceituações possíveis, os dados levantados relacionados a temática e, ao fim, as implicações da relação Direito e Economia Criativa.

\section{A CONSTITUIÇÃO FEDERAL DE 1988 E A ORDEM ECONÔMICA}

A Constituição do Estado Brasileiro de 1988 traz em seu corpo a ordem econômica como uma de suas finalidades e como um dos pilares do Estado democrático contemporâneo, bem aos moldes da evolução estrutural que sofreram os estados ocidentais no pós-revolução francesa.

Entretanto, a partir do século XIX, a mudança de perspectiva passou a dar aos Estados preocupações que vão além de estruturas puramente liberais absolutas, e (em conformidade e, pareada a ideia liberal, elenca valores e garantias para um desenvolvimento sustentável e igualitário) apresenta finalidades à ordem econômica, como por exemplo o desenvolvimento nacional, a erradicação da pobreza, a redução de desigualdades, a justiça social e a existência digna, a proteção do meio ambiente, os valores estes insculpidos no artigo 170 da Constituição Federal e em seus primeiros artigos.

Os movimentos econômicos, a princípio, não se preocupam com a estruturação de demandas sociais pura e simplesmente porque tem como objetivo primordial o aumento de suas margens de lucratividade e, diante do processo de globalização, cada vez é mais difícil enfrentar questões ambientais, sociais e trabalhistas. Ocorre que, a busca pela redução das desigualdades regionais e sociais consubstancia-se como um valor maior elencado por nossa sociedade.

Segundo Vicente Bagnoli a questão da superação das estruturas com a finalidade de redução das desigualdades (regionais e sociais) passa pela própria condição do sistema, apontando que é: 
[...] importante que a redução das desigualdades regionais e sociais, independentemente de medidas emergenciais, seja feita por meio da ordem econômica, cujos fundamentos estão na valorização do trabalho e na livre iniciativa assegurando-se assim a existência do desenvolvimento socioeconômico como forma de implementar a existência digna dos indivíduos (BAGNOLI, Vicente, 2013, p. 82)

Acontece que, passando pelos paradigmas da ordem econômica prevista na carta constitucional, a "justiça social, em síntese, deve ser adotada como um dos princípios de finalidade comunitária expressos da Constituição de 1988 a interferir no contexto da ordem econômica, visando ao implemento das condições de vida de todos até um patamar de dignidade e satisfação" (TAVARES, 2011, p. 129).

No entanto, " a mera afirmação da dignidade dos seres humanos não tem a força de fazê-los igualmente dignos" (SILVA, KNOERR, 2013, p. 438), e é neste sentido que podemos perseguir a ideia de implementação e incentivo da economia criativa.

A ideia de justiça social, conjuntamente com os ideais de livre iniciativa na ordem econômica brasileira são valores claramente insculpidos na Constituição Federal de 1988 em seu artigo 170¹.

Segundo Paula A. Forgioni (2012, p. 167): "O princípio da liberdade de iniciativa implica a liberdade de empresa, que, por sua vez, significa a liberdade de lançar-se à atividade, desenvolvê-la e abandoná-la sponte propira. " E segue a autora: "Encerra também a liberdade de contratar e a liberdade de concorrência [...]. Em suma: o princípio da livre iniciativa assegura o acesso às oportunidades de troca."

Assim, é possível identificar que a livre iniciativa consiste em liberdade econômica propriamente dita, entendido como liberdades no campo do domínio

\footnotetext{
${ }^{1}$ Art. 170 - A ordem econômica, fundada na valorização do trabalho humano e na livre iniciativa, tem por fim assegurar a todos existência digna, conforme os ditames da justiça social, observados os seguintes princípios: I - soberania nacional; II - propriedade privada; III - função social da propriedade; IV - livre concorrência; V - defesa do consumidor; VI - defesa do meio ambiente, inclusive mediante tratamento diferenciado conforme o impacto ambiental dos produtos e serviços e de seus processos de elaboração e prestação; VII - redução das desigualdades regionais e sociais; VIII - busca do pleno emprego; IX - tratamento favorecido para as empresas de pequeno porte constituídas sob as leis brasileiras e que tenham sua sede e administração no País. Parágrafo único. É assegurado a todos o livre exercício de qualquer atividade econômica, independentemente de autorização de órgãos públicos, salvo nos casos previstos em lei.
} 
empresa em seu campo econômico, o que garante aos agentes econômicos o ingresso, atuação e permanência no mercado.

Eros Roberto Grau (2011, p. 200-201) aponta que a liberdade econômica não se configura como a mais ampla e um tanto irrestrita, mas tem limitações incorporadas pelo direito de interesse estatal que sujeitarão a liberdade econômica:

\begin{abstract}
Vê-se para logo, nestas condições, que no princípio, nem mesmo em sua origem, se consagrava a liberdade absoluta de iniciativa econômica. Vale dizer: a visão de um Estado inteiramente omisso, no liberalismo, em relação à iniciativa econômica privada, é expressão pura e exclusiva de um tipo ideal. Pois medidas de polícia já eram, neste estágio, quando o princípio tinha o sentido de assegurar a defesa dos agentes econômicos contra o Estado e contra as corporações, a eles impostas.
\end{abstract}

Ademais, há um conteúdo de dignidade existencial, que direciona uma amplificação aos preceitos econômicos derivados da dignidade da pessoa humana, previsto no artigo $1^{\circ}$ da Constituição Federal, como aponta André Ramos Tavares (2011, p. 130):

\begin{abstract}
Especificamente no campo econômico, impõe-se, por força da cláusula constitucional da dignidade da pessoa humana, que a todos sejam garantidas condições mínimas de subsistência, tutela a ser prestada diretamente pelo estado aos hipossuficientes e que dele necessitem, ainda que transitoriamente.
\end{abstract}

Percebe-se um direcionamento econômico no artigo 170 da Constituição Federal visando à uma redução das bases individualistas, embora se legitime, ao mesmo tempo, a busca pelo lucro empresarial, "a empresa contemporânea [deve ressurgir] mais humanizada e voltada em suas funções não só para o interesse econômico, mas também buscando atender aos interesses sociais" (FERREIRA, 2005, p. 83).

Tem-se aliada a estas ideias a Economia Social de Mercado² "propõe um marco teórico e de política econômico-institucional que busca combinar a liberdade

\footnotetext{
2 teoria concebida pelo economista Alfred Müller-Armack. "O sistema da Economia Social de Mercado surge da tentativa consciente de sintetizar todas as vantagens do sistema econômico de mercado: promoção da iniciativa individual, produtividade, eficiência, tendência à autorregulação, com as
} 
de ação do individual dentro de uma ordem de responsabilidade pessoal e social" (RESICO, 2012, p. 112).

Importante dizer, neste sentido, que "se a economia busca o desenvolvimento da pessoa e consequentemente a do país, tanto a concorrência quanto o lucro podem ser fator de maior igualdade social. A empresa é, desta forma o catalizador destas propostas" (CAVALCANTI, 2002, p. 4).

Aliada a todo o cabedal jurídico econômico previsto no artigo 170 da Constituição Federal, há que se atentar a temática deste trabalho, que se alia a possibilidade da economia criativa como uma perspectiva econômica, de finalidades políticas, alinhada aos preceitos constitucionais.

\begin{abstract}
A economia criativa como estratégia de desenvolvimento, divide-se em duas abordagens complementares. A primeira se baseia no reconhecimento da criatividade e, portanto, no capital humano para promover a integração dos objetivos sociais, culturais e econômicos através de um modelo exclusivo de desenvolvimento global pós-industrial. [...] A segunda abordagem diz como as mudanças econômicas e, sobretudo, as novas tecnologias alteram os elos de ligação entre a cultura (das artes para entretenimento) e a economia, abrindo um leque de oportunidades econômicas baseadas em ações criativas. Ao contar com a criatividade individual, permite-se a formalização de pequenos negócios que apresentam poucas barreiras à entrada nos mercados, a economia criativa promove a geração de emprego e renda. (SIQUEIRA NETO, MENEZES, 2017, p. 43-44)
\end{abstract}

Esses valores que norteiam a estrutura econômica devem tomar por base a melhoria na qualidade de vida dos indivíduos, "o desenvolvimento tem de estar relacionado sobretudo com a melhora da vida que levamos e das liberdades que desfrutamos" (SEN, 2010, p. 29), sendo a economia criativa uma espécie viável dentro desta estrutura e destas perspectivas, de forma que, "a ordem econômica estabelecida e os princípios constitucionais não devem ser encarados como confortável ajuste de interesses antagônicos, mas, sim, como espaço de permanente luta pelos direitos fundamentais assecuratórios da dignidade da pessoa humana". (SILVA, KNOERR, 2013, p. 442).

contribuições fundamentais da tradição social cristã de solidariedade e cooperação, baseadas necessariamente na equidade e justiça numa determinada sociedade" (RESICO, 2012, p. 112). 
Não se pode esquecer, nesta estrutura, que a função primordial do desenvolvimento, ou a superação subdesenvolvimento tem como lema a expansão das liberdades. Não seria outra a finalidade do modelo capitalista ocidental ao qual estamos submetidos desde o rompimento com o mundo absolutista do final do século $\mathrm{XVIII}$, que não potencializar as capacidades individuais garantindo no modelo contratualista (ou do contrato social) uma potencialização das liberdades, com foco principal na potencialidade da igualdade como instrumento de inclusão (valores estabelecidos no estado social do século XX).

Assim, evidente que temos de "expandir as liberdades que temos razão para valorizar não só torna nossa vida mais rica e mais desimpedida, mas também permite que sejamos seres sociais mais completos, pondo em prática nossas volições, interagindo com o mundo em que vivemos e influenciando esse mundo" (SEN, 2010, p. 29).

Pensar os movimentos econômicos necessariamente nos leva a fazer escolhas de valores sociais de desenvolvimento enquanto sociedade, parâmetros elegidos pela Constituição, como plano central para a construção de uma sociedade mais inclusiva, justa e solidária.

Nesta toada é que podemos olhar para a economia criativa como uma aliada, não para superação, mas para o aprimoramento de modelos econômicos que, hodiernamente, não são suficientes para satisfazer os anseios da ordem econômica. A economia criativa, como deixam claros os dados a respeito de seu surgimento e crescimento, tem alcançado de forma mais bem-sucedida tais objetivos, surpreendendo no que diz respeito ao êxito de suas investidas.

\section{A ECONOMIA CRIATIVA EM NÚMEROS E SEUS CONCEITOS}

A recente guinada sofrida pelo setor tecnológico, trouxe consigo mudanças significativas que afetam diretamente o cenário econômico brasileiro, de modo que sua adaptação aos novos ditames da tecnologia deixa de ser mero anseio e passa a 
se tornar necessidade intrínseca ao exercício da atividade econômica para aqueles que pretendem se manter no mercado. Partindo desse pressuposto algumas reflexões se fazem necessárias para se pensar modelos de atividade econômica responsável e adequada às demandas sociais:

\begin{abstract}
Todo exercício de reflexão sobre a atividade econômica que se pretenda séria e consequente não pode menosprezar as desigualdades sociais e os fatores de sua sustentação e legitimação. Ainda que setores do proletariado organizado, técnicos, pequenos empreendedores tenham tido, nos últimos anos, uma inserção no mercado e na esfera pública, há uma gama enorme de pessoas que formam, para usar o termo de Jessé Souza, uma "ralé"4 de excluídos. Os instrumentos de luta dos trabalhadores organizados e qualificados não se prestam a fazer ouvir a voz dos interesses da plebe desorganizada. (SILVA, KNOERR, 2013, p. 440)
\end{abstract}

Nesse contexto de grandes transformações trazidas pelo avanço das novas tecnologias e sua dinâmica cada vez mais dominante, imprescindível que se busque novos parâmetros para se pensar a relação economia-tecnologia. Tendo em mente tal necessidade, é que se percebeu o potencial inovador e adaptador daquilo que se convencionou chamar de economia criativa, economia laranja ou economia do conhecimento.

Surgida em um contexto de crise econômica, a economia criativa foi difundida na Austrália em 1994, ocasião em que o governo australiano tentava implementar o programa Creative Nation que, conforme asseveram Zaganelli e Gantos (2015), pretendia fortalecer a herança cultural do país, bem como reconhecer a importância dos aborígenes australianos para a identidade nacional. Com essa finalidade, passouse a dar mais valor ao trabalho criativo e a implementação de novas tecnologias, assim como os seus efeitos na política cultural.

Não obstante, em 1997, foi realizado estudo acerca da economia criativa liderado pelo primeiro ministro Tony Blair, na Inglaterra, que proporcionou as iniciativas que se seguiram nesse mesmo viés e inspiraram o investimento de outros países nesse infante setor.

Ocorre que, ainda sem um conceito uníssono, o termo Economia Criativa somente ganhou relevo pela primeira vez em Londres no ano de 2001 com John 
Hawkins. Para Siqueira Neto e Menezes (2017, p. 4), a Economia Criativa é "modelo de negócio ou gestão que tem por base atividades, produtos ou serviços desenvolvidos e executados a partir de conhecimento, criatividade ou capital intelectual de pessoas individualmente consideradas".

Para a Conferência das Nações Unidas sobre Comércio e Desenvolvimento (UNCTAD), de acordo com o relatório de Economia Criativa divulgado em 2010, o termo:

[...] é um conceito em evolução baseado em ativos criativos que potencialmente geram crescimento e desenvolvimento econômico. Ela pode estimular a geração de renda, criação de empregos e exportação de ganhos, ao mesmo tempo em que promove a inclusão social, diversidade cultural e desenvolvimento humano. Ela abraça aspectos econômicos, sociais e culturais que interagem com objetivos de tecnologia, propriedade intelectual e turismo. É um conjunto de atividades econômicas baseadas em conhecimento com uma dimensão de desenvolvimento e interligações cruzadas em macro e micro níveis para a economia em geral. É uma opção de desenvolvimento viável que demanda respostas de políticas inovadoras e multidisciplinares, além de ação interministerial [...]. (UNCTAD, 2010, p. 10)

Vale apontar, nesta linha, que a economia tradicional é aquela que tem como base a indústria, comércio e agricultura e possui uma robusta regulamentação jurídico-normativa, enquanto a economia criativa não está robustamente amparada pelo direito "tem por foco o potencial individual ou coletivo de produzir bens e serviços criativos, tangíveis ou intangíveis, intelectuais e artísticos, com conteúdo criativo e valor econômico" (SIQUEIRA NETO, MENEZES, 2017, p. 4).

A UNESCO, por sua vez, no Creative Economy Report 2013 Special Edtion: Widening Local Development Pathways, relata que o termo permanece bastante amplo:

The notion is and remains a very broad one as it embraces not only cultural goods and services, but also toys and games and the entire domain of "research and development" (R\&D). Therefore, while recognizing cultural activities and processes as the core of a powerful new economy, it is also concerned with manifestations of creativity in domains that would not be understood as "cultural". (UNESCO, 2013, p. 19) ${ }^{3}$

\footnotetext{
${ }^{3} \mathrm{Em}$ tradução livre o texto diz: A noção é, e continua sendo, muito ampla, pois abrange não apenas bens e serviços culturais, bem como brinquedos, jogos e todo o domínio da "research and development"
} 
A FIRJAN (Federação das Indústrias do Rio de Janeiro) é uma organização sem fins lucrativos que conta com mais de 7.500 sociedades empresárias associadas, cuja atuação se dá em parceria com o SESI e SENAI, e segundo ela a Indústria Criativa é a:

\begin{abstract}
União entre indústria e os talentos criativos, a Indústria Criativa usa o conhecimento e a criatividade como principais recursos produtivos. Seus bens e serviços criam significados, oferecem experiências, despertam emoções e geram desejos. $E$ isso significa mais diferenciação e competitividade para a indústria, uma vez que os profissionais criativos agregam valor a produtos tão diferentes quanto automóveis, cadeiras, fechaduras e turbinas de avião. (FIRJAN, 2017)
\end{abstract}

Desta feita, apesar da pluralidade conceitual existente em torno da Economia Criativa, não há que se falar em anulação ou prevalência de um ou outro conceito, uma vez que todos eles, à sua maneira, apresentam denominadores comuns e, em última análise, corroboram com ideia de que sua implementação junto à atuação da economia tradicional, além de benefícios econômicos possui impactos em outros âmbitos:

[...] a economia criativa contribui significativamente para o desenvolvimento social, vez que as relações de trabalho ocorrem de maneira diferente da economia tradicional, valorizando o empreendedorismo e a autogestão, cuja consequência é o crescimento inclusivo e sustentável e a diversificação dos mecanismos de geração e distribuição de riquezas. (SIQUEIRA NETO; MENEZES, 2017, p. 7)

Pode-se definir a economia criativa, assim entendida, como aquele movimento econômico que sedimenta a estruturação de um segmento da economia com base nos processos humanos cognitivos intelectuais que desaguam na arte, na cultura, na tecnologia, de maneira multidisciplinar com a finalidade de propiciar novas experiências aos consumidores, ao passo que valoriza a autogestão dos recursos e

(Pesquisa e desenvolvimento). Portanto, apesar de reconhecer atividades e processos culturais como o núcleo de uma nova economia poderosa, ela também se preocupa com manifestações de criatividade em domínios que não seriam entendidos primordialmente como "culturais". 
fomenta a cultura do empreendedorismo de maneira inclusiva e sustentável aos olhos da economia.

Tendo em mente o que é e o que almeja a economia criativa, a apresentação e o conhecimento de alguns números é necessário para ilustrar o impacto e a efetivação deste novo segmento do setor econômico.

Os números divulgados pela UNESCO, em seu último relatório mundial (2018) dão conta que, as indústrias culturais e criativas, como ramo da economia em si, geram um total de 30 milhões de empregos em todo o mundo, bem como é responsável pela geração de receitas de US\$2,25 bilhões. É possível se falar ainda, com base em dados do Ministério da Cultura, que a Economia Criativa foi responsável por 3\% do PIB, em 2010, valor estimado em $R \$ 78$ bilhões e superior ao alcançado pela mineração. Ademais, neste ano foram contabilizados cerca de 400 mil empreendimentos criativos formalizados no Brasil.

A FIRJAN (2017) também disponibilizou dados extraídos do Mapeamento da Indústria Criativa, ferramenta que possibilita o cálculo dos postos de trabalho, remuneração e grau de escolaridade das profissões criativas no país, assim sendo, nos informa que em apenas 10 anos a indústria criativa cresceu quase $70 \%$, sendo que o número de profissionais criativos chegou à casa dos 900 mil em 2013, número que representa um aumento formal de $90 \%$. Ressalta ainda que o setor criativo gera $\mathrm{R} \$ 126$ bilhões ao ano, o que corresponde a 2,6\% do PIB brasileiro. Tais dados corroboram as pesquisas realizadas pelo Ministério da Cultura e reforçam o relevo da indústria criativa no resultado econômico do país.

Não há, portanto, como negar (diante dos dados levantados por órgão da indústria, comercio e da cultura no Brasil) o saldo positivo resultante da implementação da Economia Criativa junto ao âmbito de ação do setor econômico.

A inovação que se extrai da Economia Criativa se mostra como verdadeiro meio de inclusão sociocultural, além de viabilizar desenvolvimento humano e econômico de modo sustentável em diversas áreas. Nesse contexto:

A participação na atividade cultural gera uma ideia de igualdade, no sentido de que, todos precisam ter garantido seu espaço no meio social e que todos, 


\begin{abstract}
independente de outros fatores, são capazes de contribuir de forma positiva para uma sociedade plural e harmônica. Tornar os socialmente excluídos visíveis para a sociedade, primeiro, por humanizar o discurso sobre a pobreza e discriminação (dando ao excluído um rosto); segundo, por promover a conscientização dos próprios excluídos de seu papel na sociedade e de seus direitos como ser humano, tornando os sujeitos ativos da ação política. [...]A atividade cultural torna-se essencial para a superação da pobreza. Sua realização contribui para a geração de emprego e renda. Suas atividades afins promovem o acesso à educação, formam novos profissionais, incluindo trabalhadores residentes em áreas de risco social, que deixam de ser dependentes de políticas assistencialistas para se tornarem economicamente auto-suficientes. (LELIS, LÔBO, 2016, p. 753-754)
\end{abstract}

Assim, indiscutível o papel da economia criativa como instrumento apto a promover certos níveis de desenvolvimento econômico ao mesmo tempo em que se preocupa com desenvolvimento humano, garantindo e efetivando direitos, muitas vezes vistos como incompatíveis com a ótica econômica.

\title{
3.1 A ECONOMIA DO CONHECIMENTO E SEUS DESÍGNIOS
}

No dia 06 de novembro de 2018, em São Paulo, aconteceu a primeira edição do Mercado das Indústrias Criativas do Brasil (MicBR), organizado pelo Ministério da Cultura, onde foi apresentado o Relatório Mundial 2018 - Repensar as Políticas Culturais: Criatividade para 0 Desenvolvimento, que pretendeu avaliar a implementação da Convenção sobre a Proteção e Promoção da Diversidade da Expressões Culturais (2005), ratificada por 146 países, dentre eles o Brasil, que almeja fomentar a atuação dos Estados no sentido de implementar políticas públicas para o fortalecimento dos setores industriais cultural e criativo, promovendo a diversidade, as expressões culturais, a igualdade de gênero e os direitos humanos.

Dentre os objetivos elencados pelo referido relatório estão: apoiar sistemas sustentáveis de governança para a cultura; alcançar um fluxo equilibrado de bens e serviços culturais e aumentar a mobilidade dos artistas e profissionais da cultura; integrar a cultura nos marcos de desenvolvimento sustentável; e promover os direitos humanos e as liberdades fundamentais.

Nesse sentido, pode-se afirmar que o fenômeno da economia criativa, para alcançar as referidas metas, tem seu campo de atuação voltado para alguns setores 
específicos como a cultura, moda, design, engenharia, arquitetura, música, artesanato, softwares, jogos eletrônicos e demais setores relacionados à tecnologia e inovação.

Em razão dessa área de exercício, a Economia Criativa abre espaço para o novo, para a exploração do capital intelectual em detrimento do capital financeiro, gerando possibilidades infinitas de investimento criativo e inovador nos setores acima mencionados.

Há que se considerar ainda, a relevância deste novo ramo da economia para o fomento e propagação das agendas culturais, das artes, dos costumes, dos conhecimentos tradicionais locais e da divulgação de toda essa herança cultural para o mundo, fazendo disso algo rentável e propulsor de desenvolvimento econômicosocial de forma sustentável.

\begin{abstract}
Na maior parte da história humana o principal elemento de geração de riqueza foi o trabalho humano de natureza física, hoje conhecido como trabalho braçal, que por sua vez, leva a acumulação de capital que Marx definiu como mais valia. $\mathrm{Na}$ economia criativa o capital não tem o mesmo papel preponderante nas relações econômicas. Há inversão do capital com os agora bens intangíveis, em especial os recursos humanos, as bases de dado (big datas), os processos produtivos e, as tecnologias. (SIQUEIRA NETO; MENEZES, 2017, p. 23)
\end{abstract}

As ideias que guarnecem a dinâmica criativa, não pretendem romper com a experiência da economia mais conservadora, ao contrário, pretende a ela se aliar para, em conjunto, promover desenvolvimento que se atente a questões que ultrapassem a obtenção de lucro puro e simples. À vista disso, vale mencionar o potencial inclusivo existente na promoção da Economia Criativa:

Nos países em desenvolvimento, especialmente os mais pobres, a economia criativa é uma fonte de criação de emprego, proporcionando novas oportunidades para a redução da pobreza. Criadores, especialmente aqueles ligados com as artes tradicionais e festividades culturais, muitas vezes tendem a apoiar as minorias excluídas. (SIQUEIRA NETO; MENEZES, 2017, p. 38) 
Ocorre que, apesar de nitidamente se portar como meio de inovação dentro da dinâmica econômica, existem algumas barreiras que dificultam ou inviabilizam a difusão da Economia Laranja, dentre elas, encontram-se, a falta de informação e a falta de incentivo financeiro.

Partindo desse pressuposto, é necessário que se crie uma rede de informações para disseminar informações de qualidade que sejam, em certa medida, capacitantes, a fim de que haja maior interesse de investimento na área, que se mostra tão promissora.

Outro fator que obstaculiza o incentivo, é a carência de auxílio financeiro para investimento no âmbito da Economia Criativa, razão pela qual, de extrema importância tem sido a atuação do Banco Interamericano de Desenvolvimento (BID) que, criado em 1959, já objetivava melhorar vidas como uma das principais fontes de investimento econômico-social a longo prazo da América Latina e Caribe, além de realizar pesquisas e consultorias sobre políticas, capacitação e assistência técnica para os setores público e privado de toda a região.

Tamanha magnitude de sua atuação, o BID destinou mais de US $\$ 650$ milhões em empréstimos e assistência técnica para financiar mais de uma centena de projetos cujo objeto principal é a cultura. (BID, 2016)

O investimento, não só financeiro, mas também intelectual para a evolução da Economia Criativa é necessário não para o seu desenvolvimento autônomo enquanto ramo da economia, mas para incentivar a inovação e o aprimoramento dentro da própria indústria tradicional e conservadora que hoje luta com os novos desafios impostos pelo avanço tecnológico, de modo que a indústria como um todo deveria se revestir do viés criativo, com vistas a se adaptar à nova realidade hodierna.

Assim, torna-se claro para nós a imprescindibilidade de atuação do Estado e da iniciativa privada como um todo, como fomentadores da Economia Criativa, uma vez que o Estado deve efetivar o direito à educação, mola propulsora do desenvolvimento da Economia Laranja. 
Nesse sentido é que as universidades também devem desempenhar seu papel, incentivando pesquisas no âmbito deste novo ramo da economia, bem como qualificar tecnicamente aqueles que desejem se inserir na área.

Não obstante a tanto, importante ainda que se promova assim, a democratização da inovação, exterminando a ideia de que apenas as elites financeiras e acadêmicas estão aptas e discutir e promover desenvolvimento econômico, social e humano.

\section{AS IMPLICAÇÕES DA RELAÇÃO DIREITO E ECONOMIA CRIATIVA}

A experiência jurídica nos conta que, as evoluções sociais sempre andam largos passos a frente da evolução jurídica. Nesse aspecto, é certo dizer que o direito não acompanha, pelo menos não de imediato, as novas necessidades e demandas apresentadas pela mudança do cenário social.

Não foi diferente com a chegada da economia do conhecimento que, de repente, trouxe consigo grandes mudanças sociais e econômicas, se mostrando como verdadeira condutora de uma repentina alteração de paradigma impulsionada pela pressão das novas tecnologias e pela atuação inquestionável das mídias não tradicionais e sociais.

O surgimento deste novo modelo de negócios, com ares de fluidez e dinamicidade, desafiou a atuação da economia tradicional, traçando um novo perfil para os sujeitos envolvidos no processo econômico. A descentralização da possibilidade de se efetivar desenvolvimento econômico e social, fez com a Economia Criativa ganhasse cada vez mais robustez de forma a demandar tutela jurídica condizente com seu âmbito de atuação.

Tal demanda ganhou contornos mais específicos a partir da análise de institutos jurídicos destinados à proteção da antiga atividade econômica. A referida 
análise evidencia que instrumentos normativos como a Lei 9.610/1998 (Lei de Direitos Autorais), por exemplo, se prestam a tratar da proteção dos próprios direitos autorais, da propriedade intelectual, patentes e outros, o que claramente vai de encontro ao que preconiza os novos parâmetros a que se submetem o exercício criativo da atividade econômica.

Nesse sentido, percebe-se que a tutela oferecida pelo legislador diz respeito à proteção e aplicação de princípios típicos da economia conservadora, privilegiando uma análise privada e exclusiva dos meios de produção e distribuição de tudo que é produzido e/ou dos serviços que são prestados, ao passo que a tutela jurídica de que necessita a Economia Criativa se orienta pela compreensão de que não há exclusividade, tampouco há a ideia de proteção do capital intelectual como propriedade privada, tendo em vista o seu novo olhar para a atividade econômica, prestigiando os novos anseios da sociedade em lidar com as mais recentes tecnologias e as mídias sociais e as não tradicionais.

Partindo desse pressuposto, elucidativas são as palavras de Dowbor:

As novas tecnologias permitem que o conhecimento adquirido pela humanidade, sob forma de ciência, obras de arte, música, filmes e outras manifestações da economia criativa seja universalmente acessível, a custos virtualmente nulos. Trata-se evidentemente de um imenso bem para a humanidade, para o progresso educacional, científico e cultural de todos. Mas para os intermediários do acesso aos bens criativos, que controlavam a base material da sua disponibilização, houve uma mudança profunda. Em vez de se adequarem às novas tecnologias, sentem-se ameaçados, e buscam travar o uso das tecnologias de acesso, acusando quem as usa de pirataria, e até de falta de ética. Geram-se assim duas dinâmicas, uma que busca aproveitar as tecnologias para generalizar o enriquecimento cultural, e outra que busca através de leis, da criminalização e do recurso ao poder do Estado, travar a sua expansão. A tecnologia torna os bens culturais cada vez mais acessíveis, enquanto as leis, por pressão organizada dos intermediários, evoluem simetricamente para cada vez mais dificultar o acesso. (DOWBOR, 2009, p. 2)

Não existem dúvidas de que o tratamento dado à Economia Criativa não condiz com o tratamento exigido pela economia tradicional, de forma que não pode a lei pretender tutelar aquela assim como tutela a propriedade de bens materiais. Essa tentativa configura "imenso prejuízo social para pequenos lucros privados" 
(DOWBOR, 2009). É necessário, portanto, ter consciência de que simplificações da situação não bastam para que essa lacuna legislativa seja preenchida, não basta se valer de analogias para respaldar situações não análogas.

A título de exemplificação vale observar o andamento das novas tecnologias e da estrutura do big-data. É interessante notar como se dá a dinâmica jurídica clássica frente a novas estruturas, primordialmente com relação a estruturas tecnológicas que evoluem em uma velocidade que a norma jurídica tem grande dificuldade de acompanhar.

Em 1957, o primeiro computador chegou ao território brasileiro, adquirido pela prefeitura de São Paulo, com a finalidade de aprimorar os serviços de emissão de contas do Departamento de Águas e Esgotos. "A notícia foi veiculada em primeira mão por O Estado de São Paulo no artigo intitulado '2.400 multiplicações por minuto'”. (PEREIRA, 2014)

Obviamente que para a então nova tecnologia chegar ao lar dos brasileiros ainda levaria algum tempo, entretanto, somente em 1998 que a legislação sobre direitos autorais incluiria os programas de computador dentro de sua gama de proteção.

Como programas de computador, podemos pensar, por exemplo, nos sistemas operacionais (que são aqueles programas responsáveis pelo gerenciamento de recursos, armazenamento, processadores de dados nas maquinas) que criam uma plataforma comum aos programas utilizados (Windows; Mac OS e; Linux são exemplos de sistemas operacionais).

Enquanto sistemas operacionais como o Windows e o Mac OS obedecem a uma estrutura clássica de relações econômicas e jurídicas, o Sistemas Operacionais Linux vai na contramão da economia clássica e operam sob o vértice da economia criativa. "Ao contrário de seus concorrentes mais famosos, o Linux não foi desenvolvido para fins comerciais e seu software e desenvolvimento são feitos em código aberto, o que significa que qualquer pessoa pode criar e distribuir aplicativos para ele" (KURTZ, 2015). 
Com relação ao segundo, podemos observar a dificuldade de se estruturar as normas jurídicas clássicas para limitação e regulamentação de uma estrutura linguística computacional própria nem sempre compreensível ao ser humano comum, haja vista o problema da regulamentação da proteção de dados intentada pelo marco civil da internet, Lei 12.965.

A lógica da nova dinâmica econômica, diferentemente do que se está habituado a pensar com os direitos de propriedade intelectual, que configuram um direito de domínio público restrito e indisponível por um certo (longo) período de tempo, clama por uma proteção menos obstaculizada, pregando pela supremacia do compartilhamento do conhecimento em detrimento de sua monopolização pelas "elites empreendedoras". Nada mais lógico, portanto, do que trabalhar com a ideia de Creative Commons, apta a corroborar com a defesa e efetivação da disseminação de conhecimento, até porque, o que se tem como inovação hoje, só é assim considerado em razão de todo um conhecimento anterior já disseminado por alguém, de forma que não se pode falar em construção isolada de conhecimento, tendo em vista se tratar de construção coletiva. Ideia que se reforça com as palavras de Dowbor, 2009, "a inovação é um processo socialmente construído, e deve haver limites à sua apropriação individual".

Assim sendo, é preciso discutir um modelo de proteção jurídica que contemple o viés descentralizado da Economia Criativa, de forma a reconhecer e promover a solidariedade, a liberdade e o compartilhamento de informações, adequando-se à realidade dos novos meios de produzir, contratar, distribuir e lucrar, à exemplo do que se pode alcançar com as redes sociais, aumentando-se, por conseguinte, as chances de promoção de desenvolvimento econômico sustentável atento à proteção e promoção dos direitos humanos, e efetivação das garantias fundamentais.

\section{CONCLUSÃO}


O trabalho desenvolvido tratou da ordem econômica na Constituição de 1988, estabelecendo suas relações a partir da economia criativa como um caminho para o desenvolvimento econômico, social e ambiental, promovendo e efetivando direitos fundamentais, ou seja, aqueles valores insculpidos nos artigos 5 e 170 do Texto Constitucional.

Apresentou-se inicialmente aquelas questões relacionadas à ordem econômica na Constituição, bem como questões relativas à economia criativa, suas conceituações possíveis, os dados estatísticos a ela relacionados e, por último, as variadas implicações da relação Direito e Economia Criativa.

A questão proposta para o presente trabalho se relacionou com a verificação do potencial da economia criativa como promotora da efetivação dos valores econômicos constitucionais ao mesmo tempo em que garantisse estabilidade sustentável, e justiça social.

Percebeu-se, no decurso da pesquisa, que a economia criativa estabelece bases para um desenvolvimento sustentável, com dados estatísticos muito promissores, ao mesmo tempo em que tem como norte estabelecer valores intrínsecos de cunho social, desenvolvimento nacional, entre outros valores fundamentais.

Não obstante, a economia criativa contribuiu para a promoção de grande aumento no PIB nacional, bem como foi, em parte, responsável pela diminuição do índice de desemprego no Brasil, além de promover maior autonomia para aqueles que nela investem ou venham a investir, prescindindo de vínculo empregatício, gerando maior interesse daqueles que precisam se reinventar para obter oportunidades no mercado de trabalho.

A economia criativa mostra ainda, sua particular forma de tratar economicamente a cultura e outros vieses de uma sociedade plural, permitindo que se propague e enalteça a multiculturalidade, enxergando-a, sob uma ótica inclusiva, como meio para que pessoas promovam desenvolvimento econômico e social a partir daquilo que Ihes é familiar culturalmente. 
Notadamente, portanto, a economia do conhecimento busca preencher as lacunas socioeconômicas deixadas pela experiência econômica tradicional, de forma que tem alcançado resultados nunca antes vistos, privilegiando neste processo, setores, indivíduos e características que antes não seriam considerados na variável econômica como instrumento de aprimoramento do exercício da atividade econômica no Brasil que, a partir do viés criativo, homenageia e efetiva princípios inerentes à ordem econômica e aos direitos fundamentais/humanos.

Os objetivos se mostraram fundamentais para o desenvolvimento do trabalho, mostrando haver uma relação imbricada entre os preceitos da economia criativa, desenvolvimento socioeconômico, sustentabilidade e direitos fundamentais.

\section{REFERÊNCIAS}

BAGNOLI, Vicente. Direito econômico. 6. ed. São Paulo: Atlas, 2013.

BRITISH COUNCIL. The brazilian creative economy: situation analysis and evaluation od Newton-Funded creative and social entrepreneurship programme. British Council, 2018. Disponível em: $<$ https://www.britishcouncil.org.br/sites/default/files/brazilian_creative_economy_onlin e_sem4_new.pdf>. Acesso em: 27 de fev. 2019.

CAVALCANTI, Thais Novaes. Ética empresarial: fundamentos constitucionais de uma ordem econômica socialmente responsável. Disponível em: <http://www.academus.pro.br/professor/thaisnovaes/material/Texto_\%C3\%89tica\%2 0empresarial_Thais\%20Novaes\%20Cavalcanti_Academus.pdf>. Acesso em: 30 julho 2014

CONFERÊNCIA DAS NAÇÕES UNIDAS SOBRE COMÉRCIO E DESENVOLVIMENTO. Relatório de economia criativa 2010. UNCTAD, 2010. Disponível em: < https://unctad.org/pt/docs/ditctab20103_pt.pdf>. Acesso em: 27 de fev. 2019.

DOWBOR, Ladislau. Da propriedade intelectual à economia do conhecimento. Artigos por Ladislau Dowbor. Nov. 2009. Disponível em: < http://dowbor.org/2009/11/da-propriedade-intelectual-a-economia-do-conhecimentooutubro.html/>. Acesso em: 08 de mar. 2019. 
FERREIRA, Jussara Suzi Assis Borges Nasser Ferreira. Função social e função ética da empresa. Revista Jurídica da UNIFIL, Centro Universitário Filadelfia, Londrina, v. II, n. 2, p. 67-85, 2005.

FIRJAN.O programa indústria criativa. Conselho Nacional SESI, 06 de mar. 2017. Disponível em: < http://conselhonacionaldosesi.org.br/2017/03/o-programa-industriacriativa-firjan/>. Acesso em 27 de fev. 2019.

FORGIONI, Paula Andrea. A evolução do direito comercial brasileiro: da mercadoria ao mercado. 2. ed. rev. atual. ampl. São Paulo: Revista dos Tribunais, 2012.

GAMES: oportunidades e ameaças de um setor em expansão. It Forum 365, 10 de mar. 2016. Disponível em: < https://www.itforum365.com.br/mercado/gamesoportunidades-e-ameacas-de-um-setor-em-expansao/>. Acesso em: 27 de fev. 2019.

GIDDENS, Anthony. As conseqüências da modernidade. tradução de Raul Fiker. São Paulo: UNESP, 1991.

GRAU, Eros Roberto. A ordem econômica na constituição de 1988. 16. ed. rev. atual. São Paulo: Malheiros, 2014.

IADB. Presidente do BID destaca o impacto das indústrias criativas na economia e na geração de empregos. Banco Interamericano de Desenvolvimento, 04 de out. 2016. Disponível em: < https://www.iadb.org/pt/noticias/comunicados-deimprensa/2016-10-04/construir-solucoes-2016-industrias-criativas\%2C11584.html>. Acesso em: 27 de fev. 2019.

LANÇAMENTO de relatório mundial da UNESCO, reafirma contribuição da cultura para o desenvolvimento sustentável. UNESCO, 08 de nov. 2018. Disponível em: < http://www.unesco.org/new/pt/brasilia/about-this-office/single-

view/news/launch_of_global_report_of_unesco_reaffirms_contribution_of/>. Acesso em: 27 de fev. 2019.

LELIS, Henrique Rodrigues; LÔBO, Edilene. A dimensão cultural dos direitos humanos e a efetivação do estado democrático de direito. Revista UNICURITIBA, Unicuritiba, Curitiba, v.3, n. 44, p. 734-758, 2016. Disponível em: $<$ http://revista.unicuritiba.edu.br/index.php/RevJur/article/view/1894/1262>. Acesso em: 19 mar. 2019.

LINUX: tudo que você precisa saber antes de começar a usar. Tech Tudo, 24 mar. 2015. Disponível em: < https://www.techtudo.com.br/noticias/noticia/2015/03/linuxtudo-o-que-voce-precisa-saber-antes-de-comecar-usar.html>. Acesso em 13 mar. 2019. 
ORGANIZAÇÃO DAS NAÇÕES UNIDAS PARA A EDUCAÇÃO, A CIÊNCIA E A CULTURA. Criative economy report 2013 special edition: widenin local development pathways (2013), New York, UNESCO, 2013. Disponível em: <http://www.unesco.org/culture/pdf/creative-economy-report-2013.pdf>. Acesso em: 27 de fev. 2019.

ORGANIZAÇÃO DAS NAÇÕES UNIDAS PARA A EDUCAÇÃO, A CIÊNCIA E A CULTURA. Repensar as políticas culturais: criatividade para o desenvolvimento. Relatório global da Convenção de 2005. UNESCO, 2018. Disponível em: <https://unesdoc.unesco.org/ark:/48223/pf0000266025/PDF/266025por.pdf.multi>. Acesso em: 27 de fev. 2019.

PALADINO, Gina Gulineli. Economia criativa e novos desafios do desenvolvimento. Futuri9. Jul. 208. Disponível em: < http://futuri9.com/2018/07/12/economia-criativa-enovos-desafios-do-desenvolvimento/>. Acesso em: 27 de fev. 209.

PEREIRA, Lucas de Allmeida. Os primórdios da informatização no Brasil: o "período paulista" visto pela ótica da imprensa. Scielo, Universidade Federal do ABC, Santo André, v. 33, n. 2, p. 408-422, 2014. Disponível em: < http://www.scielo.br/pdf/his/v33n2/0101-9074-his-33-02-00408.pdf>. Acesso em: 13 mar. 2019.

RESICO, Marcelo F. Introdução à economia social de mercado. Tradução de Ana Beatriz Torres. Rio de Janeiro: Konrad-Adenauer Stiftung, 2012.

SEN, Amartya. Desenvolvimento como liberdade. Tradução de Laura Teixeira Motta. São Paulo: Compania das Letras, 2010.

SILVA, Marcos Alves da, KNOERR, Viviane Coêlho de Séllos. Responsabilidade social da empresa e subcidadania pautas para uma reflexão de índole constitucional. Revista Jurídica - UNICURITIBA, Unicuritiba, Curitiba, v.2, n.31, p. 435-453, 2013. Disponível em:

http://revista.unicuritiba.edu.br/index.php/RevJur/article/view/611/472>. Acesso em: 19 mar. 2019.

SIQUEIRA NETO, José Francisco; MENEZES, Daniel Francisco. Ensaio de Economia Criativa e Colaborativa e sua Regulação. Belo Horizonte: Arraes, 2017.

TAVARES, André Ramos. Direito Constitucional Econômico. 3. ed. Rio de Janeiro: Forense, 2011.

UNESCO. UNESCO lança, no Brasil, relatório mundial 2018 - repensar as políticas culturais: criatividade para o desenvolvimento. UNESCO, 31 de out. 2018. Disponível em: <view/news/unesco_launches_in_brazil_the_2018_global_report_resh/>. Acesso em: 27 de fev. 2019. 
ZAGANELLI, Bárbara Martins; GANTOS, Marcelo Carlos. Economia laranja e comunicação: uma nova partilha do valor da informação na era da criatividade. Organicon. São Paulo, v. 12, n. 23, p. 88-97. 2015. Disponível em: < http://www.revistas.usp.br/organicom/article/view/139297/134638>. Acesso em: 25 de fev. 2019. 